\section{INSTRUMENT DEMOS: A DREADED NECESSITY}

Robert J. Hessler

Hessler Technical Service, Stamford CT

I've been selling high tech products for about 20 years and I've never quite gotten over the fear of the phrase: "I'd like to go to the plant for a demo."

As many of us have said in the past, there's no such thing as a good demo, only one which didn't disintegrate beyond all recognition. Every salesperson I know has his or her favorite stories of incredible happenings when the "Proximity Effect" takes over. (For the unknowing, the Proximity Effect states that the more closely the customer approaches a demo instrument, the more likely it is to self-destruct.)

My most memorable demo occurred when I was working with a French company selling semiconductor manufacturing equipment. I arrived with customers from the States and the first morning we were standing outside the demo lab passing the time until we were given the all clear from the instrument technician. As we conversed, an acrid odor permeated the lobby and the lights in the demo lab seemed to dim a bit. The odor became overpowering.

Suddenly, the technician burst though the lab door shouting "Instrument au feu!! Instrument au feu!!!" followed by a huge puff of smoke. The beast was actually smoking! Luckily, it was only a defective tansformer and the difficulty was repaired in short order, put really - on fire!

Luckily, not all these hunks of stainless steel we sell are as vicious as to actually smoke at the customer.

But while an instument demo is a necessary happening which the vendor needs to provide for the satisfaction of the customer, the customer, in turn, must remember that he has certain responsibilities to make the demo as meaningful as possible so the vendor is given a fair opportunity to

\section{BARRY SCIENTIFIC} $\angle a B_{6}$ CATHODES

with MULTI-THOUSAND HOUR LIFETIMES

Extended Lifetime / Superior Quality

High Brightness / Low Energy Spread

Exceptional Stability / Easy Operation

Stress-Free Carbon Mounting

Extensive Application Notes on Request

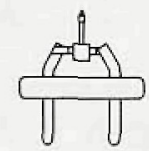

TUNGSTEN SEM/TEM FILAMENTS

Best Quality / Fully Annealed

Precision Aligned / Strain Free

New Packaging / Individually Secured

Filaments Visible in Opened Box

Easy-To Use Handling Tool

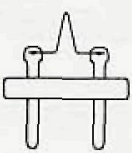

\section{WEHNELT APERTURES \\ Precision Polished Ta Apertures

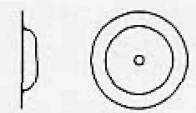

Exclusive Retail Distributor for North America

I BARRY SCIENTIFIC

P.O. Box 173, 58 Streeter Road, Fiskdale, MA USA 01518

Tel (508) 347-9855 1-800-348-2257 Fax (508) 347-8280

Products Manufactured By demonstrate his wares. Some of these responsibilities can be best illustrated by extremely fond memories:

$\checkmark$ The customer who opened his briefcase the first morning of a two day demo, unloaded 387 samples, and announced, "Most of these aren't important but I thought if things went real well we could have a look at them." (Excellent, our instrument is at its best when running unimportant samples and they should be extremely meaningful for your boss and the purchasing decision maker).

$\checkmark$ "I can't see Ni or S with my Auger or ESCA but the guys in the plant say that they're pretty sure there should be some in these." Eight delightful hours later, "well, maybe I should go back to the plant and ask the guys if they're really sure it's in there." (And while you're at it, ask about the rest of the Periodic Table.)

$\checkmark \quad$ Unloading a bucket of gook on the lab bench, "we've been trying to find out what's in this stuff for years." (Have you tried tasting it?)

$\checkmark$ And most memorable, "Boy, if we can solve this problem, l'll have no trouble selling this instrument to management." (Probably not, nor to the Nobel Prize Committee, either.)

If the customer insists upon presenting vendors with impossible problems or pet projects, he will leave the demo without knowing anything more about the instrument than when he arrived. He will, probably without realizing it, have a good evaluation of how well the guy in the lab can run the instrument.

But, is he going to buy an instrument or hire an operator?

Prospective buyers should remember these cardinal rules about demos: $\checkmark$ Take only well characterized samples to a demo. How in the world can you tell how well the instrument is performing if you don't know anything about your samples?

$\checkmark$ Take a suite of samples which contain some easy to run and well known standards. Something from NIST, if practical. Know what good results should look like so you can recognize them when you see them. Also, these kinds of samples provide data which is easily comparable from vendor to vendor.

$\checkmark$ Don't test the vendor's ability to prepare samples. If you have tricky samples, prepare them yourself before you leave your lab or be ready to prepare them at the vendor's site. I've seen half a day wasted mounting a sample. Even then we could not trust the resulting data.

$\checkmark$ Stay with the instrument. Sometimes unexplained or unwanted coffee breaks can be utilized to mask awkward adjustments or design glitches.

$\checkmark \quad$ Listen to and watch the operator. He is not only obtaining data for you but he is also demonstrating what skill's you will need to operate the instrument if you should purchase it.

$\checkmark$ Last, if you want to demo for a particular product discuss it carefully with the local salesperson. Don't wing it. Without a doubt, call the person who will be running the demo and discuss the samples you will be bringing to him. As a courtesy, send the samples ahead so there are no embarrassing delays while sample mounting problems are solved.

Try to put yourself in the vendor's position.

While you may believe you are doing the vendor a favor by allowing him to demonstrate his gear, remember you are also learning much about a product for which you will have to make a purchasing decision.

And for your careers sake, you need to make that decision with as much intelligence as you can glean from your visit. 


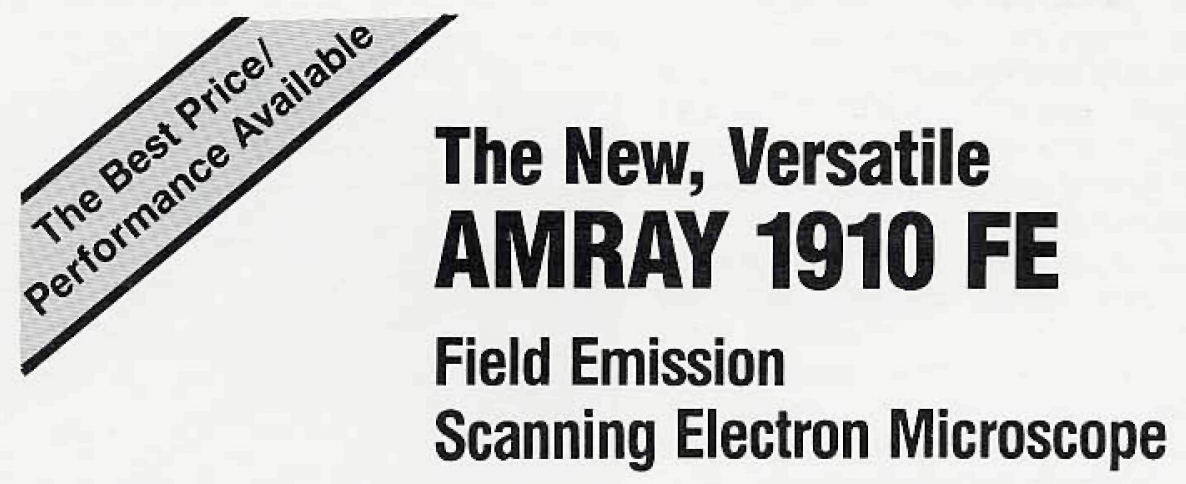

The Ideal System for Nondestructive

Examination and Analysis of

Specimens Up to 6" in Diameter...

- Attractive price-significantly lower in cost than comparable field emission SEMs ... with no compromise in performance

- Large specimen chamber

- Superior resolution-1.5 nm at $30 \mathrm{KV}$

- AMRAY 305 Schottky field emission gun

- 4" motion stage

- Energy dispersive X-ray compatible

For full information, contact




the same reaction site as the temperature changes. This type of stability also allow nanofabrication (here making lines, trenches, raised objects, etc., on the surface of some substate, here Si) to take place more rapidly due to an acceleration of temperature related diffusion processes on the sample surface. The stability of the stage is important to reduce distortion in the features due to specimen drift. The pyramid shown in Figure 2 is made by merely stopping the probe during the scan and adjusting the bias between the tip and the specimen. Atoms on the surface are attracted to the probe and the pyramid results.

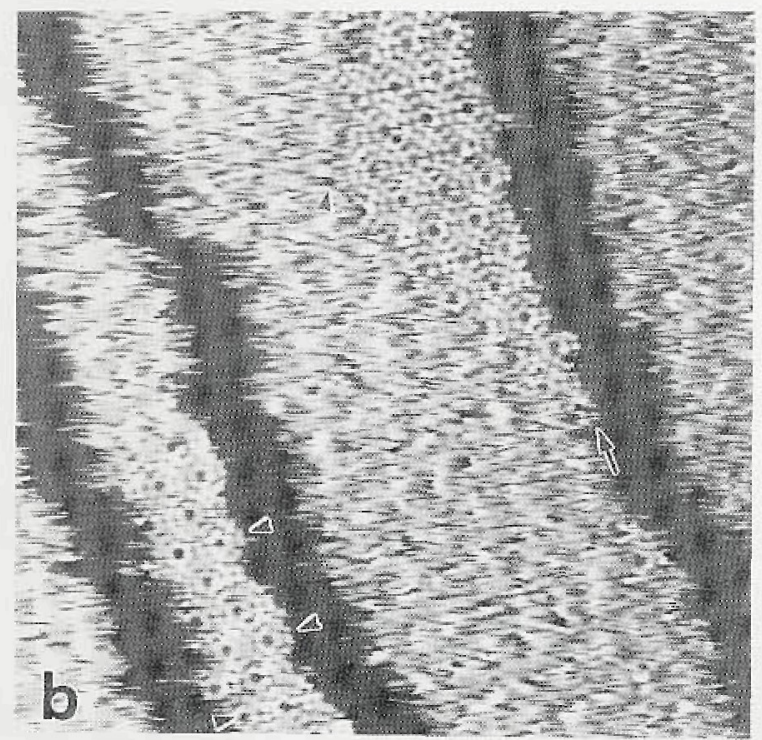

Figure 1B: Follows Figure 1A by 16 seconds. Note the movement of the ledge (step). The ordered structure is growing as the temperature is lowered.

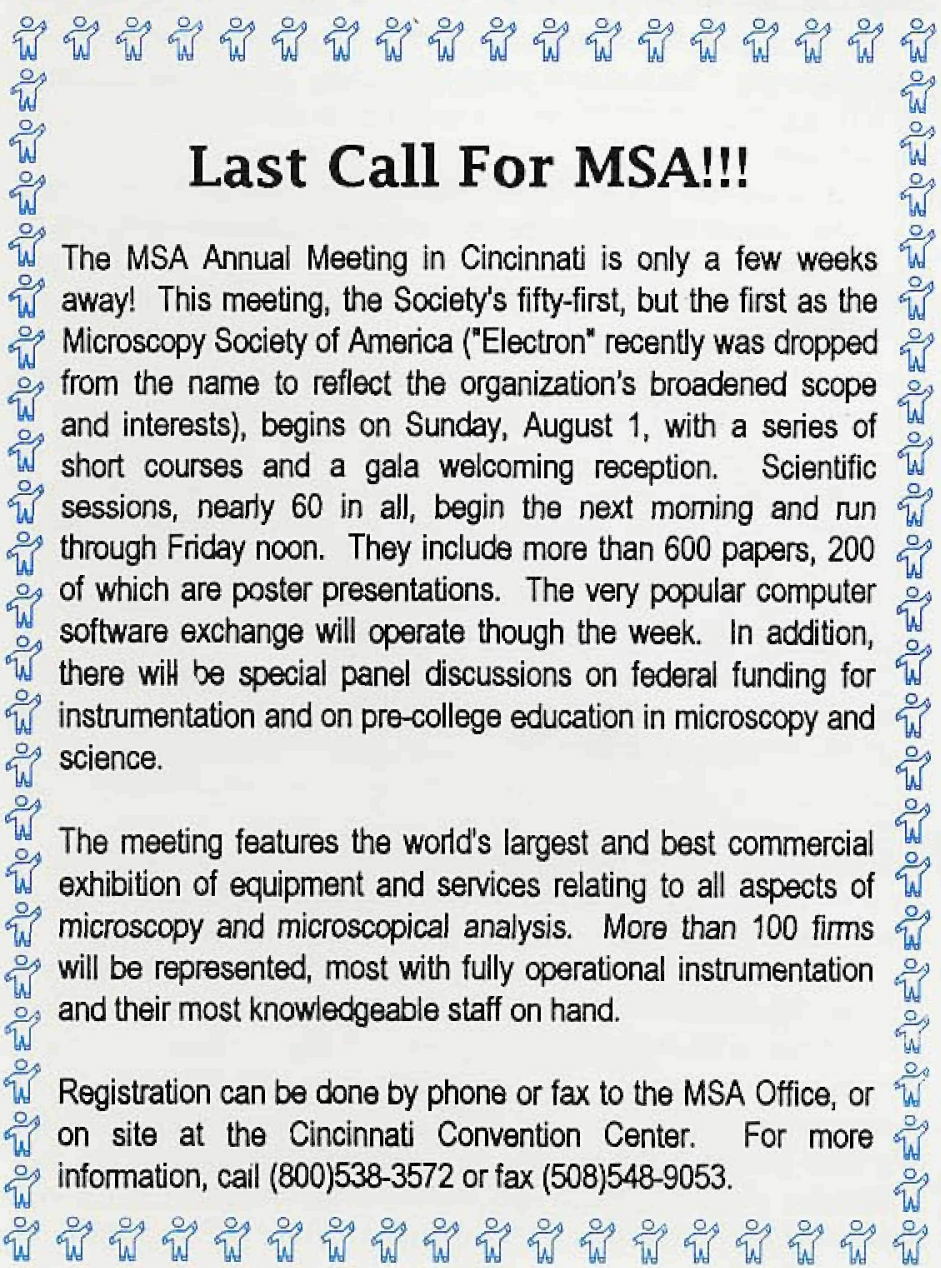

Subsequent scans reveal its structure. Specimen temperature is $600^{\circ} \mathrm{C}$. If the temperature is left stable at $600^{\circ} \mathrm{C}$, the pyramid will disappear. If the structure is quenched, the pyramid will be stable. This type of nanofabrication may be especially important in designing future AFM tips for truly ultrahigh AFM resolution

The capability described above can be duplicated on the JEOL JSTM4500/4600VT. An operating version of this UHV high temperature microscope will be shown at MSA this year in Cincinnati.

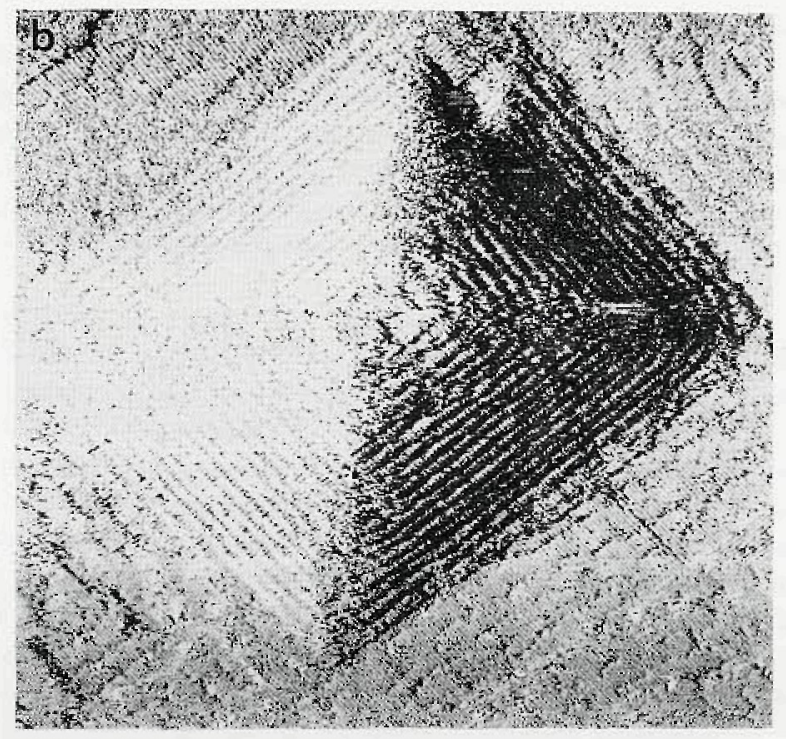

Figure 2: The pyramid is made at $600^{\circ} \mathrm{C}$. Image is then recorded at $600^{\circ} \mathrm{C}$ Approximate base dimensions are $90 \times 80 \mathrm{~nm}$. Pyramid height is $5 \mathrm{~nm}$.

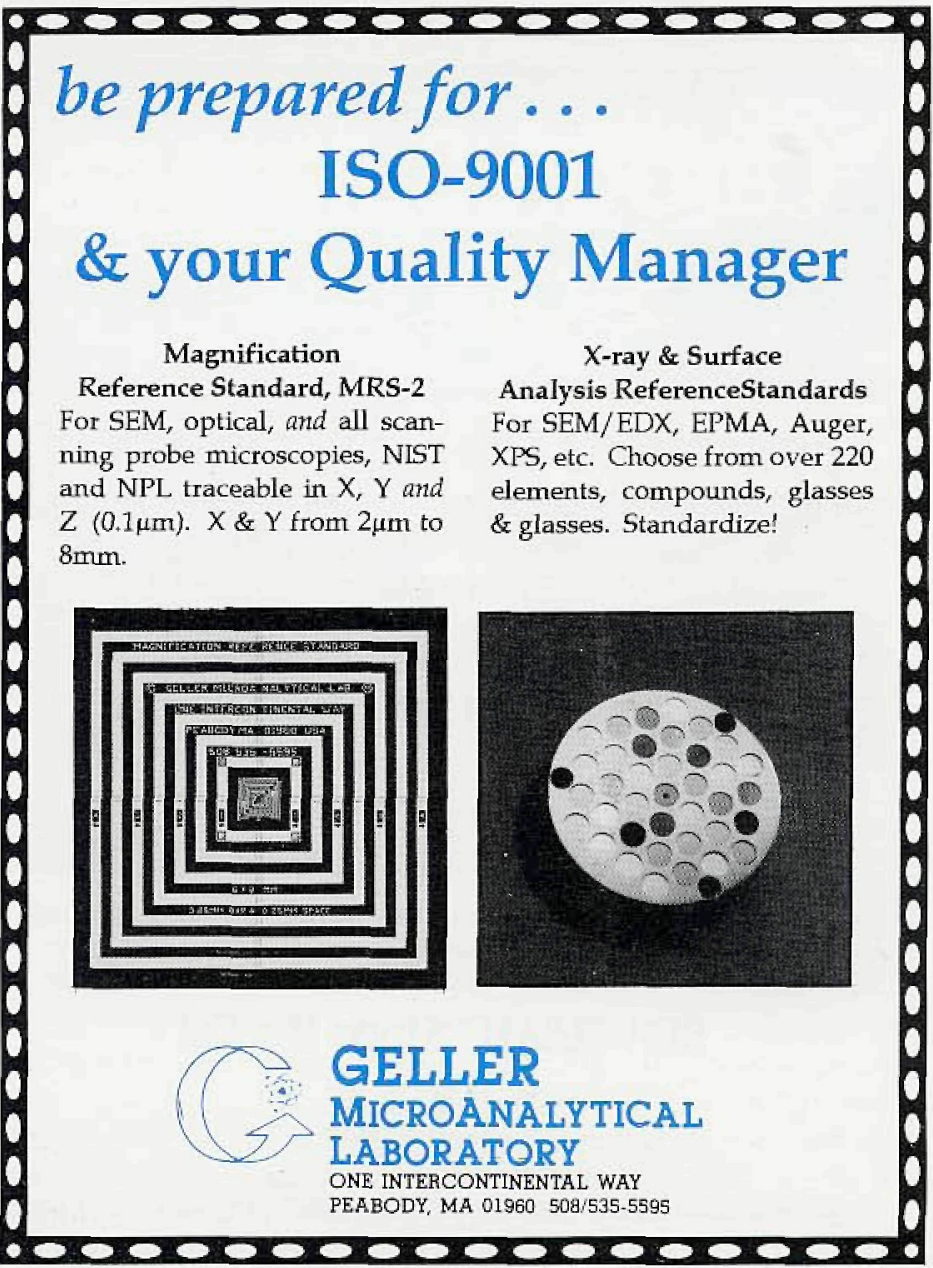




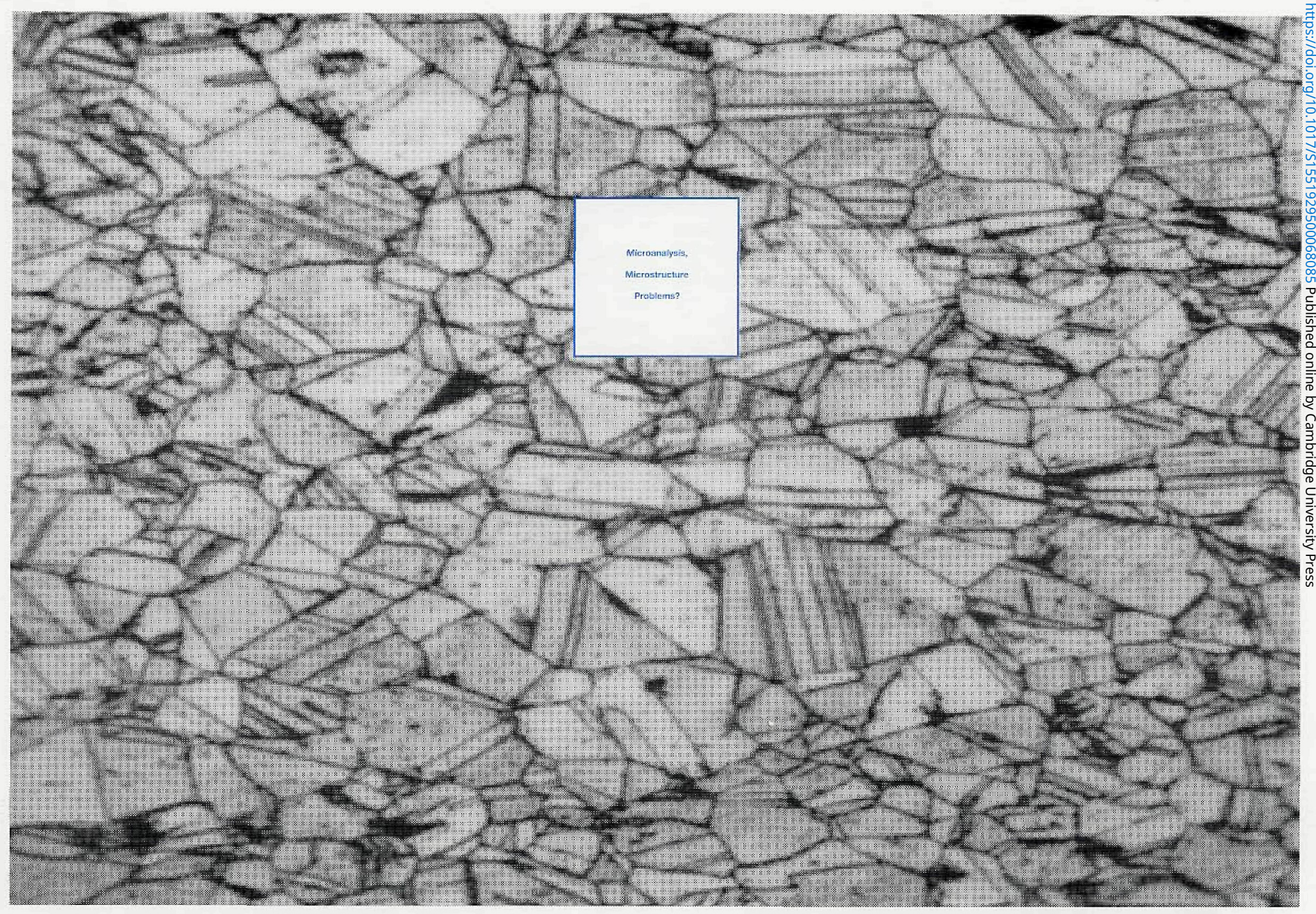

\section{Take a Closer Look ... . PGT Has the Answer!}

\section{-Metals •Pharmaceuticals •Ceramics •Bioscience •Geology •Mineralogy •Polymers and Plastics -Textiles •Electronics •Semiconductors •Forensics •Environmental •Advanced Materials}

When you need solutions to microscopy problems, turn to the recognized leader in Advanced Microanalysis Applications. The power, speed and true multitasking of the Sun SPARCstation ${ }^{\circledR}$ applied to your analysis, automation and networking requirements:

-Computer Aided Microscopy •Reliable X-ray Microanalysis •Particle Size Analysis -ASTM Grain Sizing •SEM Automation•Coatings Analysis • Stereo Depth Measurement -Fractography •CD Measurement •True Color Image Analysis •Stage Automation

PGT IMIX and IMAGIST - Dedicated to solving analytical problems

Princeton Gamma-Tech, Inc.

1200 State Road, Princeton, NJ 08540

Tel: 609/924-7310 Fax: 609/924-1729 